\title{
The Next Step Toward Patient-Centeredness in Multidisciplinary Cancer Team Meetings: An Interview Study with Professionals
}

\author{
Paulus AF Geerts' \\ Trudy van der Weijden (iD ${ }^{2}$ \\ Wilma Savelberg ${ }^{3}$ \\ Melis Altan ${ }^{4}$ \\ Giorgio Chisari ${ }^{4}$ \\ Diana Ricarda Launert ${ }^{4}$ \\ Hannah Mesters ${ }^{4}$ \\ Ylva Pisters ${ }^{4}$ \\ Mike van Heumen ${ }^{4}$ \\ Raoul Hermanns ${ }^{4}$ \\ Gerard MJ Bos (iD) \\ Albine Moser ${ }^{2,5}$ \\ 'Department of Internal Medicine, \\ Division of Hematology and School \\ GROW, Maastricht University Medical \\ Centre, Maastricht, the Netherlands; \\ ${ }^{2}$ Department of Family Medicine, \\ Maastricht University, School CAPHRI, \\ Maastricht, the Netherlands; ${ }^{3}$ Oncology \\ Centre, Maastricht University Medical \\ Centre, Maastricht, the Netherlands; \\ ${ }^{4}$ Faculty of Health, Medicine and Life \\ Sciences (FHML), Maastricht University, \\ Maastricht, the Netherlands; ${ }^{5}$ Zuyd \\ University of Applied Sciences, Heerlen, \\ the Netherlands
}

Background: Patient-centeredness is essential in complex oncological multidisciplinary team decision-making. Improvement seems to be needed, while there is a lack of knowledge about health care providers' needs for improvement.

Objective: To explore multidisciplinary team members' perspectives on the need to improve patient-centeredness in complex decision-making, and subsequently the strategies to enhance it. Methods: This was a qualitative descriptive interview study. The participants were twentyfour professionals who attended multidisciplinary cancer team meetings weekly. The setting was five multidisciplinary teams (gastrointestinal, gynecological, urological, head and neck, and hematological cancer) in a Dutch academic hospital. Data were collected by semistructured interviews and were analyzed with a combination of inductive and deductive content analysis.

Results: The participants voiced the need for additional information (patient-centered information, patients's needs and preferences, individualized medical information) during the multidisciplinary team meeting, to be more patient-centered in the decision-making conversation with the patient following the meeting, and for more information following the meeting to support patient-centeredness. The strategies, which mostly originated from the needs, were categorized as organization, decision-making, and communication. The most prominent strategies were those aimed at collecting and using patient-centered information, and to facilitate the decision-making conversation with the patient following the multidisciplinary team meeting.

Conclusion: Our findings highlighted the need to improve patient-centeredness in oncological multidisciplinary teams and provided a comprehensive overview of strategies for improvement, supported by multidisciplinary team members. These strategies emphasize involvement of patients throughout the continuous process of decision-making for patients with cancer. These strategies may be implemented in other oncological multidisciplinary teams, taking in mind the local needs. Future research may help to prioritize the strategies and to determine and evaluate the effect on endpoints, like patient or professional satisfaction, shared decision-making, and on the decision that was made.

Keywords: patient-centered care, decision-making, patient care team, cancer, patient care, multidisciplinary team

\section{Plain Language Summary}

Patient-centeredness has been designated to improve health care quality and equality. Patientcenteredness means that health care becomes more oriented to the patient as an individual and aims to be respectful and empowering. It implies the individual participation of the 
patient and is built on a relationship of mutual trust, sensitivity, empathy, and shared knowledge.

Important decisions in the care for cancer patients are usually first discussed within a multidisciplinary team meeting: a meeting with different clinicians that are experts on the disease, diagnostics, and treatments. Thereafter, the team's diagnostic or treatment recommendations are discussed with the patients.

It is known that patient-centeredness may need to be improved in team meetings. Therefore, we explored the needs of the team clinicians regarding improvements in patientcenteredness and discussed possible strategies for improvement with them. We interviewed 24 clinicians with different background specialties from five multidisciplinary teams involving different types of cancer.

The clinicians needed more information about the patient as a person to base their recommendations on, for example, information about the situation at home, or thoughts of the patient about possible treatments. Furthermore, they needed decisionmaking and reporting during the meeting aiming at helping them to be more patient-centered in the consultation with the patient that follows the meeting. For example, by discussing more than one treatment option and reporting the pros and cons of each option, so they could then be discussed with the patient; these, and many other strategies may help multidisciplinary cancer teams to improve on patient-centeredness.

\section{Introduction}

In the cancer care setting, multidisciplinary teams (MDTs), also called tumor boards, have been widely introduced to facilitate team discussion and decision-making regarding cancer diagnosis, treatment, and follow-up. In Europe and North America, it is the current standard of care to discuss each patient in a MDT meeting. ${ }^{1,2}$ Health care professionals involved in cancer care, such as physicians and nurses, attend these meetings to enable interdisciplinary information exchange. MDTs are now widely accepted and their implementation is associated with changes in cancer assessment, diagnosis, and management. ${ }^{3-5}$ Intensive interdisciplinary teamwork is also associated with a higher score on patient-centeredness. ${ }^{6}$

Patient-centeredness is a biopsychosocial approach and attitude that aims to deliver care that is respectful, individualized, and empowering. It implies the individual participation of the patient and is built on a relationship of mutual trust, sensitivity, empathy, and shared knowledge. Therefore, the core attributes of patient-centredness are the biopsychosocial perspective, treating the patient as a unique person and a sustainable and genuine patientcaregiver relationship. ${ }^{7}$ Patient-centered care is regarded an important feature of consistent, high-quality health care. ${ }^{8}$ Previous research has shown that patientcenteredness may need to be improved in MDT decisionmaking. ${ }^{5,9-15}$ This need mostly originated from MDT quality improvement studies. Discussing patientcentered factors, such as psychosocial and psychological information and patient preferences, was shown to be relevant for MDT decision-making and implementation of the MDT treatment recommendation. ${ }^{5,9-12}$ Subsequently, observational studies showed the lack of patient-centered information and patient preferences in MDT meetings. ${ }^{13-15}$ The need for patient-centered information was voiced by MDT members in one interview study. ${ }^{15}$ Additionally, an important reason for nonimplementation of MDT advice was a lack of information about patient preferences. ${ }^{17-24}$ These findings underline the importance of patient-centered information exchange in the MDT meeting to make decisions in line with patients' goals and preferences, especially in complex decision-making. ${ }^{5}$

Although there seems to be room for improvement in patient-centeredness on oncological MDTs, several barriers are recognized from the health care provider's perspective. First, nurses often try to take on the role of patient advocate, but more senior MDT members may dismiss them. ${ }^{5,9-11}$ Second, physicians are not always familiar with the patient's situation. ${ }^{13,25}$ Third, time pressure at MDT meetings can rush decision-making. ${ }^{5,10,13,26}$ This affects the quality of the decision-making, due to reduced task-oriented communication and reduced socio-emotional interactions between MDT members. ${ }^{27,28}$ Fourth, although MDT members may have an open attitude towards psychosocial aspects and patient preferences, they may perceive several regulatory or organizational restraints. ${ }^{26}$ Finally, in most cases, only a single treatment option is communicated to the patient, although a broader spectrum of possible treatment options has been discussed. ${ }^{13}$ These barriers may hinder the successful implementation of strategies to improve patient-centeredness. ${ }^{29}$

Earlier, several studies provided strategies to improve MDTs, mostly aimed at improving the decision-making procedure and effectiveness. ${ }^{5,9,12,30-32}$ Two studies provided strategies aimed explicitly at patient-centeredness. ${ }^{16,25}$ These studies focused on patient representation at the meeting, knowing patient preferences for treatment, and communicating with patients about MDT recommendations. They did not cover the whole spectrum of patientcenteredness and it's attributes. ${ }^{7}$ 
To further enrich the strategies that may improve patient-centeredness in oncological MDTs, more empirical information is required about MDT members' needs for patient-centeredness and about what strategies might address these needs. Therefore, the aim of this study was to obtain insights into the perspectives of MDT members for:

- the need for improvement of patient-centeredness in oncological MDT meetings, and,

- a broad spectrum of strategies that may improve patient-centeredness in complex oncological MDT decision-making.

\section{Materials and Methods Design}

We designed a qualitative descriptive study using semistructured interviews to examine patient-centeredness on oncological MDTs. To explore the strategies, we used a guiding framework based on key publications on patientcenteredness in MDTs and expertise of the research team. $5,7,12,18,25,33-36$

\section{Setting}

The setting was a Dutch academic hospital that has local non-academic as well as regional academic referral functions. Members of five different MDTs participated: gastrointestinal, gynecological, urological, head and neck, and hematological cancer. The MDT meetings are periodic meetings physically attended by hospital professionals involved in cancer care, such as a medical oncologist, hematological oncologist, radiation oncologist, surgical oncologist, nurse practitioner, radiologist, pathologist, gastroenterologist, and many residents. Compared to the others, the gastrointestinal and head and neck MDT meetings were attended by a relatively large variety of these professionals. The hematology MDT meeting was attended mostly only by hematologists and either a pathologist or radiologist. In all MDT meetings, patients were mostly discussed at mandatory moments according to national guidelines: The first presentation, after surgery, and at disease recurrence or a new decision moment. In all MDT meetings, patients were also discussed that were referred from other hospitals and had not yet attended the academic clinic, although this was far more common in the gastrointestinal and gynecological MDT meeting. Registering a patient for the MDT meeting was usually performed by the treating physician or nurse practitioner. At the gastrointestinal MDT meeting, this was strictly a paper referral, while at the gynecology MDT meeting, physicians from the referring hospital attended the meeting by video conversation to discuss the case. At the gastrointestinal and gynecology MDT meeting, the nurse practitioner or attending physician introduced the patient case, while at the other three MDT meetings, this was usually done by the physician in charge of the patient. In general, a geriatrician, palliative care specialist, social worker, or the general practitioners did not attend the meetings. Patients do not attend the meetings. The MDT members discussed patient cases with the intention of generating diagnostic or treatment advice for the physician in charge of the patient.

\section{Participants}

The participants were 24 hospital professionals who participate weekly in oncological MDT meetings ("MDT members"). We used purposive sampling based on which of the five MDTs the MDT member attends, as well as the MDT members' profession (such as specialist, specialist in training, or nurse practitioner), discipline, age and gender. We intended to select at least two influential members of each MDT, such as the chair and participants involved in most case discussions. We excluded medical students. MDT members were contacted face-to-face or by phone for participation in the interviews and were informed briefly about the research goal beforehand.

\section{Data Collection}

Data were collected in a period of three months. Seven (bio)medical or health science students, who were selected on the basis of previous study results and motivation for this project, and two Ph.D. candidates performed the interviews. The research team included experts in the field of patient-centeredness, clinicians, and experts in qualitative research. One Ph.D. candidate (WS) was already an experienced interviewer. The other eight interviewers were trained by the senior members of the research team. Twenty-one interviews were attended by two members of the research team, and three interviews were attended by one member. In the case of two attendants, one was the lead-interviewer, and the other was the observer who took field notes and occasionally supported the interviewer by asking in-depth questions. The research team members, including the interviewers, observed each participating MDT meeting at least once 
prior to the interviews to get acquainted with the context. Characteristics of the MDT case discussions were collected using a standardized data collection sheet (Supplement 1).

The interviews were performed following an interview guide with open questions (Supplement 2). ${ }^{37}$ The interview guide was based on a consultation of experts within the research group and the strategies section also on the guiding framework (Supplement 3). The first two interviews were used for piloting the interview guide, after which some adaptions were made. In the interviews, we used the term "patient-centeredness" to mean recognizing the individual patient's needs, preferences, values, and concerns regarding cancer treatment while also considering the patient's biological, psychological, and social context. At the start of the interview, the interviewer asked the MDT member about his or her definition of patient-centeredness and explained our definition, if needed. We used the term "non-medical information" for psychosocial or psychological information. Characteristics like comorbidity, performance status, age, and gender were referred to as "medical information". The interviews were conducted in either Dutch or English, based on the language preference of the participant.

In the first part of the interview, the MDT member was asked to elaborate on their experiences with and views on the current level of patient-centeredness on the MDT, and their perceived needs felt to improve it. Subsequently, the interviewer used so-called complex cases to stimulate and illustrate this elaboration. These complex cases were derived from caselevel observation data of the participating MDT meetings. Two complex patient cases were selected for each MDT, based on predefined selection criteria: the cases fulfilled at least one or two of the following inclusion criteria: ${ }^{38}$ duration of discussion longer than average (based on local data on the average duration of discussion per patient), the number of MDT members involved was more than two, more than one treatment option was discussed further, or the content of the discussion included non-oncological issues.

In the second part, the interviewer asked the MDT member to provide and discuss strategies that spontaneously came to mind for improving patient-centeredness in MDT meetings. Then, a printed list of strategies according to the guiding framework could be presented in case no (additional) strategies spontaneously came to mind. The MDT member was asked to reflect on one or a few of these strategies.

The interviews lasted 30 to 45 minutes and were performed at a location of the participants' convenience. MDT members were asked to give their unrestricted views, without being hindered by feasibility restrictions. The interviews were audiotaped and transcribed verbatim.

\section{Data Analysis}

Data were analyzed by combining inductive and deductive content analysis: ${ }^{39,40}$ First, two research team members read and coded the interview transcripts independently. To analyze the perceived needs for improvement, text fragments were highlighted and coded inductively. To analyze the strategies, an unconstrained categorization matrix was used with preexisting codes following the guiding framework for the deductive analysis. Additionally, new codes were created inductively for text fragments describing strategies not yet on the list. Second, the two team members compared these codes, and a final code for each fragment was generated by consensus. These codes were summarized in a codebook. For each subsequent coded transcript, the most recent codebook version was used and updated. This provided one final codebook (available from the authors on request). Field notes were used to gain additional insight, mainly contextual information that was relevant to understanding the interview transcript. They were not transcribed or coded. Third, for further analysis, the codes regarding the needs and strategies were both organized into new categories and subcategories that represented the most relevant themes. These categories were discussed recurrently within the research team until a consensus was reached on the meaningful presentation of the findings.

Twenty-two initial interviews were performed. To assess data saturation, a batched analysis based on codebook development was performed. ${ }^{41}$ The first 15 interviews were preliminarily analyzed as "batch one" and it was decided to perform two additional interviews. We regarded the data was saturated when no new codes emerged. The second batch of seven interviews provided additional codes, although few, to the first. The two additional interviews did not provide any new codes, and therefore, data saturation was confirmed.

NVivo version 11.0 for Mac was used for analysis.

\section{Trustworthiness}

To secure credibility, prolonged engagement with the interview setting and MDT members was guaranteed by MDT observations. Furthermore, two research team members had been member on one or more MDTs, and one had a supporting role in many MDTs. The selection of MDT members from different disciplines provided different perspectives (data and sources triangulation). Researchers with different backgrounds and levels of research experience were 
involved (investigator triangulation). Peer debriefing was realized by a recurrent discussion of the analysts' findings within the research team. Furthermore, a member check was done by sending the participating MDT members a copy of the interview transcript for comments and by discussing the summary of results with each MDT. Patients from four national cancer patient organizations (colon, gynecological, prostate, and head and neck cancer) were invited to two focus group sessions. It turned out that the patients acknowledged the strategies and no new strategies arose. Finally, reflective process notes were made in the analysis process, and all codebook versions were saved.

To secure transferability, rich information about the research setting and the research team was provided, and all (sub) categories in the analysis were provided with quote exemplars. The COREQ checklist was used for thorough reporting.

\section{Ethical Considerations}

The Medical Ethical Commission of Maastricht University Medical Centre confirmed that full ethical approval for the study protocol was not indicated. Verbal consent was obtained before the start of the interview from all participants, just before the audiotape started. The participants consented to anonymized responses being published. Data were analyzed and reported confidentially and anonymously and were stored afterward in a protected data area.

\section{Results}

Twenty-four of the 25 MDT members who were approached consented to participate. Their characteristics are displayed in Table 1 and the MDT case discussion
Table I MDT Members' Characteristics $(n=24)$

\begin{tabular}{|l|l|l|}
\hline & Characteristic & Total \\
\hline MDT - N & & \\
& Gastroenterology & 8 \\
& Gynecology & 4 \\
& Urology & 2 \\
& Head and neck & 3 \\
& Hematology & 7 \\
\hline Discipline $-\mathrm{N}$ & & \\
& Hematologic oncologist & 6 \\
& Medical oncologist & 2 \\
& Radiation oncologist & 3 \\
& Head and neck surgical oncologist & 3 \\
& Gastrointestinal surgical oncologist & 2 \\
& Gynecological surgical oncologist & 3 \\
& Urological surgical oncologist & 1 \\
& Gastroenterologist & 1 \\
& Nurse practitioner & 3 \\
\hline Age range $-\mathrm{yr}$. & & $29-63$ \\
\hline Gender - N & Male & 10 \\
& Female & 14 \\
\hline
\end{tabular}

Abbreviation: MDT, multidisciplinary cancer team.

characteristics in Table 2. The needs and strategies are discussed consecutively.

\section{Needs}

Analysis of the MDT members' needs for improvement of patient-centeredness on MDTs resulted in three categories: Information in the MDT meeting, decision-making, and information following the MDT meeting (Table 3).

Table 2 MDT Case Discussion Characteristics

\begin{tabular}{|l|l|l|l|l|l|}
\hline MDT & $\begin{array}{l}\text { Total Cases } \\
\text { (Number) }\end{array}$ & $\begin{array}{l}\text { Average Duration and } \\
\text { Range of Case Discussion } \\
\text { (min:sec) }\end{array}$ & $\begin{array}{l}\text { Average } \\
\text { Participating } \\
\text { Clinicians (n) }\end{array}$ & $\begin{array}{l}\text { More Than One } \\
\text { Treatment Option } \\
\text { Discussed (\%) }\end{array}$ & $\begin{array}{l}\text { Use of Non- } \\
\text { Medical } \\
\text { Information (\%) }\end{array}$ \\
\hline Gastroenterology & 24 & $4: 43(1: 20-11: 30)$ & 6 & 35 & 29 \\
\hline Gynecology & 28 & $2: 58(1: 00-6: 40)$ & 4 & 18 & 18 \\
\hline Urology & 22 & $4: 08(0: 50-14: 10)$ & 5 & 39 & 18 \\
\hline Head and neck & 31 & $5: 30(2: 05-11: 10)$ & 7 & 15 & 6 \\
\hline Hematology & 24 & $4: 41(1: 10-10: 25)$ & 4 & 43 & 25 \\
\hline Total & 129 & $4: 25(0: 50-14: 10)$ & 5 & 27 & 19 \\
\hline
\end{tabular}

Abbreviation: MDT, multidisciplinary cancer team. 
Table 3 Overview of Needs for Patient-Centeredness

\begin{tabular}{|l|l|}
\hline Category & Subcategory \\
\hline Information in the MDT meeting & $\begin{array}{l}\text { Need for patient-centered information } \\
\text { Need for knowing goals and preferences } \\
\text { Need for individualized information. }\end{array}$ \\
\hline Decision-making & $\begin{array}{l}\text { Need for patient-centeredness in consultation with the patient } \\
\text { Need for patient-centeredness during MDT decision-making process } \\
\text { Resistance to more patient-centeredness }\end{array}$ \\
\hline Information following the MDT meeting & $\begin{array}{l}\text { Need for more information following MDT meeting } \\
\text { Need to register/document information } \\
\text { Need to discuss information with the patient }\end{array}$ \\
\hline
\end{tabular}

Abbreviation: MDT, multidisciplinary cancer team.

\section{Information in the MDT Meeting}

Almost all MDT members expressed a need for additional information being available in the MDT meeting, which would enable individualization of the MDT recommendation, eg, by reporting two alternative recommendations. First, most of these needs regarded patient-centered information, such as psychosocial information or information about the patient's personal circumstances. Second, the need to know the patient's goals or preferences was put forward, which some members made concrete in that one should "know" or "see" the patient in person. Third, the need for individualized medical information, for example, the most recent performance status, how well a patient had recovered from earlier treatment, or the results of a geriatric assessment. This need was mostly felt by members from MDTs that included patients that were referred from another clinic without a consultation with one of the MDT members. This example summarizes various information needs:

\footnotetext{
"Yeah, when you are deciding whether you want to do an operation - yes or no - of course, then you have to know about her fitness. And if you want to give chemotherapy, you should know about the social situation: Whether the patient lives alone, whether she still has some level of autonomy, can do things by herself. I think that's the most important to have a good idea about a social situation and what she can do." [Participant 12, MDT 4]
}

\section{Decision-Making}

These needs regarded the decision-making process during the MDT meeting or the process with the patient. Mostly, the MDT members felt a need for patient-centeredness in the consultation with the patient following the MDT meeting, as the physician in charge and the patient could then individualize the MDT recommendation:

"Because all the MDT can say: 'well option A is most valid, but if the patient does not want that, it is option B'. Then the final decision is when you are with your patient and not when you are with the MDT." [participant 11, MDT 3]

The MDT members stated that the case discussions at the MDT meeting should primarily be medically based. Some expressed the need for patient-centeredness during the MDT decision-making process. They stated that some cases, mostly surgical ones, needed a technical, medical discussion closely adhering to guidelines, while other cases needed a more patient-centered discussion, tailoring the recommendation to the individual. They voiced the need for a shared understanding to what extent patientcenteredness applies to each case discussion.

In contrast, others expressed resistance to the need for more patient-centered decision-making: For example, when only one realistic treatment alternative was available, when withholding treatment was medically not desirable or when the trade-offs were complicated to a level that the professional expected the patient not being equipped to take the decision. Another MDT member indicated that the MDT advice should not be primarily guided by the patient's preferences, as they might change over time during the course of the disease or treatment. One MDT member expressed the need to keep the patient's autonomy limited, as he believed patients might make decisions they would later regret.

\section{Information Following the MDT Meeting}

The MDT members expressed a need for the transfer of information from the MDT to the patient or physician in 
charge. They wished for more information being registered in the MDT report to support their understanding of the case discussion. For example, the pros and cons that were discussed and a conclusion of the recommendation(s) should be clearly reported. One MDT member indicated a need to register the psychosocial information that was discussed, as it would help to determine the applicability of the recommendation:

"Then what is written in the MDT report is not always what has been discussed in those five minutes, because it is a resume. And then I miss the psychosocial part in the letter. Especially with patients who have little social support and where a very complicated extensive treatment is recommended." [participant 25, MDT 4]

Additionally, one MDT member indicated the need that MDT recommendations would be discussed with the patient as neutral as possible, as the preference for a certain recommendation by a professional might influence the patient's choice, and then all options would not be equally considered.

\section{Strategies}

Analysis of the strategies identified three main categories for improvement of patient-centeredness in MDTs: organization, decision-making, and communication. Each category consisted of subcategories, which are presented in Table 4 and described in detail below, which also depicts the corresponding need for each subcategory.

\section{Organization}

The MDT members suggested organizational improvements to ensure a more effective and, in turn, more patient-centered MDT meeting. Many considered people management: They recommended that various types of professionals may attend the meeting, provide information during the meeting or have a consultation with the patient beforehand. To provide medical and patient-centered information, preferences, or clinical assessment information, the general practitioner (GP) or geriatrician were most often mentioned. Also, although less frequently, the anesthetist, nurse (practitioner), social worker, and psychologist were mentioned.

"For example, you could arrange a consultation with a social worker, or someone who can speak about the patient's thoughts, or a geriatrician. That would add something. (...) To know how they are in life. If they want to prioritize survival or quality of life." [participant 2, MDT 2]

Some MDT members recommended involving the GP for goal clarification, although most regarded this as their own responsibility. In two MDTs where the attendance of the physician in charge was less frequent and more referral patients were seen, all participants recommended the attendance of a clinician who was familiar with the patient.

Additional strategies involved information management, such as using a video call with the GP. Some surgeons recommended displaying the patients' photograph on the screen, mostly for patient recognition. A hematologist warned not to estimate performance status based on the photograph, as it may not resemble the patient's current status.

Also, MDT members recommended strategies about meeting management, for example regarding the chair: first the chair should specifically pay attention for patientcenteredness and stimulate the other participants in this respect when needed. Second, the chair may in general more optimally perform this task when the MDT culture allows strict, well-organized chairing. One MDT member suggested delegating some chair tasks to a co-chair:

"The secretaries do that wrong because often medical terms are mentioned. Sometimes they know them, but sometimes they hear new words. That is not good; it takes time, also for the other attending professionals. So it would be better to do it [chairing] with two people." [participant 16, MDT 1]

Some MDT members recommended scheduling more meeting or preparation time. Others suggested strategies that may save time: more structured patient presentation (obligation of) completeness of the information document that is used to present the patient, and only brief discussions on patient cases that seem to clearly fit to the guidelines.

Finally, organizational strategies involving education. First, the fellows and some specialists focused on the role of the specialist in training. They emphasized involving and supervising them towards patient-centeredness, thereby also providing them autonomy to discuss their own recommendations with the MDT. They recommended giving feedback, preferably after the meeting. One of the MDT members emphasized their pre-MDT meeting, where cases were already discussed in a postgraduate training setting. Second, some MDT members recommended training the MDT participants individually or as a team, amongst others, in shared decision-making. 
Table 4 Overview of Strategies to Improve Patient-Centeredness

\begin{tabular}{|c|c|c|c|}
\hline Category & Subcategory & Strategy & Corresponding Need \\
\hline \multirow[t]{4}{*}{ Organization } & $\begin{array}{l}\text { People } \\
\text { management }\end{array}$ & $\begin{array}{l}\text { Involve staff with an attention to patient-centered information (nurse, psychologist, social worker, } \\
\text { geriatrician, general practitioner, clinician familiar with patient). } \\
\text { Delegate goal clarification to general practitioner. } \\
\text { Attendance of clinician who is familiar with the patient. }\end{array}$ & $\begin{array}{l}\text { Patient-centered } \\
\text { information. } \\
\text { Knowing goals and } \\
\text { preferences. } \\
\text { Individualized } \\
\text { information. }\end{array}$ \\
\hline & $\begin{array}{l}\text { Information } \\
\text { management }\end{array}$ & $\begin{array}{l}\text { Show picture of patient on screen. } \\
\text { Enable teleconferencing for eg general practitioner, physician from referring hospital. }{ }^{a}\end{array}$ & $\begin{array}{l}\text { Patient-centered } \\
\text { information. } \\
\text { Individualized } \\
\text { information. }\end{array}$ \\
\hline & $\begin{array}{l}\text { Meeting } \\
\text { management }\end{array}$ & $\begin{array}{l}\text { Organize more or longer MDT meetings to relieve time pressure. } \\
\text { Guarantee adequate MDT preparation time for physician in charge of patient. } \\
\text { Introduce structured patient presentation. } \\
\text { Guarantee access to patient information timely before MDT meeting, also with referrals. } \\
\text { Oblige completing patient file before MDT meeting. } \\
\text { Chair is responsible for patient-centeredness. } \\
\text { Co-chair with secretary role. } \\
\text { Chair works following strict principles. }\end{array}$ & - \\
\hline & Education & $\begin{array}{l}\text { Train MDT on Shared Decision-Making (SDM). } \\
\text { Train chair for patient-centeredness. }{ }^{a} \\
\text { Exchange best practices between MDTs. } \\
\text { Teach patient-centeredness to interns/residents. } \\
\text { Teach chairing task to interns/residents. }\end{array}$ & - \\
\hline \multirow[t]{3}{*}{$\begin{array}{l}\text { Decision- } \\
\text { making }\end{array}$} & MDT process & $\begin{array}{l}\text { Select patients for detailed discussion or short discussion. } \\
\text { Discuss alternative treatments with pros and cons. }{ }^{\text {a }} \\
\text { Case close off with recommendation, arguments/rationale, and level of agreement. }{ }^{\text {a }} \\
\text { Do not aim for consensus in complex cases, but eg, provide a list with options. }{ }^{\text {a }} \\
\text { Postpone decision to next meeting in referral patients instead of giving a conditional advice. }\end{array}$ & $\begin{array}{l}\text { Patient-centeredness } \\
\text { during MDT decision- } \\
\text { making process. }\end{array}$ \\
\hline & Patient process & $\begin{array}{l}\text { Elicit patient values, preferences, and goals with tools. }{ }^{a} \\
\text { Make asking values, preferences, and goals a routine. } \\
\text { Use decision aid. } \\
\text { Support of GP to clarify values. }{ }^{\text {a }} \\
\text { Invite the patient to MDT meeting, }{ }^{\text {a }} \text { or have two consecutive meetings with and without patient. }\end{array}$ & $\begin{array}{l}\text { Patient-centeredness in } \\
\text { consultation with the } \\
\text { patient. } \\
\text { Patient-centered } \\
\text { information. } \\
\text { Knowing goals and } \\
\text { preferences. } \\
\text { Individualized } \\
\text { information. } \\
\text { To discuss information } \\
\text { with the patient. }\end{array}$ \\
\hline & $\begin{array}{l}\text { Patient } \\
\text { advocacy }\end{array}$ & $\begin{array}{l}\text { Assign a patient advocate (nurse, GP, physician in charge). }{ }^{\mathrm{a}} \\
\text { Define the role of the patient advocate, eg to present the patient, to clarify the values, to ask } \\
\text { patient-centered information, to advocate the patient's opinion. }\end{array}$ & $\begin{array}{l}\text { Patient-centered } \\
\text { information. } \\
\text { Knowing goals and } \\
\text { preferences. }\end{array}$ \\
\hline Communication & $\begin{array}{l}\text { Information to } \\
\text { MDT }\end{array}$ & $\begin{array}{l}\text { Presence of professional with info, eg, nurse, assistant, general practitioner, physician in charge, } \\
\text { geriatrician. } \\
\text { Standardize collection of patient-centered information or individualized medical information by: } \\
\text { - Questionnaire, tool, or list. } \\
\text { - Text block in MDT forms. } \\
\text { - Work-up-day to gather all information in one day } \\
\text { Determine a standard presentation format including the mentioning of patient-centered } \\
\text { information. } \\
\text { All involved specialties prepare relevant cases. }\end{array}$ & $\begin{array}{l}\text { Patient-centered } \\
\text { information. } \\
\text { Knowing goals and } \\
\text { preferences. } \\
\text { Individualized } \\
\text { information. }\end{array}$ \\
\hline
\end{tabular}

(Continued) 
Table 4 (Continued).

\begin{tabular}{|l|l|l|l|}
\hline Category & Subcategory & Strategy & Corresponding Need \\
\hline & $\begin{array}{l}\text { Information } \\
\text { following MDT }\end{array}$ & $\begin{array}{l}\text { Standardize the written report, including options, pros and cons, arguments, or uncertainties. } \\
\text { Chair supervises thorough reporting. } \\
\text { Designate a co-chair for thorough reporting. } \\
\text { Clinic appointment with most relevant specialties following MDT meeting ("carrousel meeting"). } \\
\text { Physician in charge discusses MDT report with patient, eg, options, pros and cons, uncertainty. } \\
\text { Disclose MDT written report to the patient. }\end{array}$ & $\begin{array}{l}\text { More information } \\
\text { following MDT meeting. } \\
\text { To discuss information }\end{array}$ \\
& &
\end{tabular}

Note: ${ }^{a}$ items (partially) derived from the list of strategies.

Abbreviations: MDT, multidisciplinary cancer team. GP, general practitioner.

However, some MDT members were doubtful about training, for example because they believed it would not be suitable for experienced clinicians:

"A specific training? I do not know, I think it is also a bit part of the personality, like how much time you take. You cannot really train it. Although maybe a bit of strategy can be helpful, but then I think you have to do it early in the medical education before people become a doctor." [participant 11, MDT 3]

\section{Decision-Making}

The MDT members recommended strategies to improve the decision-making process during the MDT meeting, or with the patient and strategies about patient advocacy.

The first strategy for decision-making in the MDT meeting was to adequately select the patients who need more elaborate decision-making as opposed to more straightforward decisions. The second, when possible, to discuss treatment alternatives or recognize that alternatives are available and provide these in the MDT report instead of formulating one single recommendation. This would leave room for the physician in charge to discuss the alternatives and the related pros, cons, and uncertainties with the patient:

"Yes or when there is a conflict, yes that's possible, that you leave this space open. Because then you give room to the physician in charge to consider the options that have been discussed. That could be pleasant for some people. 'Actually, I prefer option a, but in certain circumstances option b is also fine.' And that you get approval of the MDT to do so." [Participant 4, MDT 3]

Some MDT members emphasized not to turn discussing treatment alternatives into a routine obligation, but only when realistic alternatives are available.

The third strategy was to check and agree on the recommendation(s) in the report at the end of each case discussion by all attendees or by the chair. Finally, one MDT member of a MDT with many referral patients suggested postponing a decision to the next meeting when not all required information was available, instead of making hypothetical recommendations based on limited information.

Decision-making with the patient: Almost all MDT members responded to the listed strategy to invite the patient to the MDT meeting. All MDT members, but one nurse practitioner, rejected this strategy. Most thought the patient would be distressed and/or the professionals would not be able to discuss the case as frankly as they would otherwise. The recommended strategies focused on clarifying patients' treatment values and goals, although there was no consensus among the MDT members within and between the various MDTs. The methods that were discussed to clarify values and goals were using a decision aid, using the Outcome Prioritization Tool, ${ }^{30}$ consulting or delegating it to the GP, and by just asking the patient directly in the consultation. Here, a radiotherapist describes how to time the use of a decision aid:

"Regarding patient decision aids: of course, it is supportive for a patient. And most if it is already given before the consultation, because after a consultation with the physician the patient is already biased. (...) It provides opportunities to participate more [in decision making]." [participant 20, MDT 5]

Finally, the MDT members recommended strategies on patient advocacy, mostly by a nurse practitioner. The patient advocate could be a provider of values, preferences, and patient-centered information:

"Well, because he [the GP] is medically oriented and is not as the patient is in the meetings, but he is presenting from the patient view, and he can add more patient-centered information. Maybe we didn't know that the patient is abusing alcohol or drugs and they say "do you know that the patient ..." You know sometimes it is medical information, but it's lacking. So he is kind of the spider on the web, and he knows everything from the medical 
information and the specialist kind of view and from the patient, so he is the perfect solution to give us more appropriate and needed information." [Participant 19, MDT 1]

As an alternative to being a passive information provider, the nurse practitioner could present the patient, to become more involved in the case discussion, or even actively represent the patient, thereby defending the patients' views.

\section{Communication}

Two communication subcategories were recognized: information from the patient to the MDT and information processing following the MDT.

Various strategies about information to the MDT were recommended. The most frequently mentioned strategies were using a questionnaire, tool, or list to collect this information, whether or not in combination with a text block in the MDT patient file. Complementing the strategy to involve various professionals in the MDT meeting, some MDT members suggested delegating the task of collecting this information to a professional. Other strategies were a standard presentation format including all relevant information types, obliging MDT preparation for the participants so they would already be familiar with the most important information and a "work-up-day" where all information is gathered in one day:

"So maybe we need to move back to do everything in one day and then followed by the MDT meeting. I also read in a book that is what the patient wants. Then you have anesthetics, fitness test, geriatric screening available at the MDT meeting. As they sometimes help in the MDT decision making." [participant 24, MDT 1]

Additionally, some MDT members expressed resistance to the standardization of information collection. They emphasized that it should not become a burden for the professional or the patient and that the information should add value to the MDT discussion. In line with this, another MDT member recommended using a summary of the information, just as with medical information like CT scans.

To process the information following the MDT meeting, two groups of strategies were recommended. The first group involved strategies to improve the written report of the MDT by documenting different options, arguments, or patient-centered information. The second group contained strategies on how to communicate this information to the patient. Most MDT members thought the physician in charge should discuss the options, pros and cons, or uncertainties with the patient. Some MDT members recommended that the patient would have a joint consultation with specialists involved in the specific case:

"So how would I ideally see this? That we would have a joint consultation. So two specialists sit together with a patient. And then you can give the information in the most objective way to the patient." [participant 20, MDT 5]

Finally, one MDT member suggested giving the patient the written report of the MDT meeting.

\section{Discussion}

In this study, we first explored MDT members' perspectives on the need for improvement of patient-centeredness in oncological MDT meetings, and secondly, their perspectives on strategies that may improve patient-centeredness in complex oncological MDT decision-making. We identified three needs: Information in the MDT meeting, decision-making, and information following the MDT meeting. The improvement strategies regarded the organization, decision-making, and communication. Mostly, the strategies corresponded with a need. The following novel strategies were recommended: first, designating a co-chair with secretary role; second, pre-selecting patients for a detailed or short discussion; third, designating a patient advocate who has a clear defined role; and finally, a joint consultation after the MDT meeting. Our findings may be used as a practical guide to apply or formulate strategies in other hospitals. As the starting point for this study was the local situation, we recommend assessing the local needs and taking them in mind while using our findings. Our group currently participates in a Dutch collaboration, aiming to further implement patient-centeredness in MDTs in the Netherlands by developing and evaluating an integrated oncological decisionmaking model, supported by the Dutch Cancer Society (KWF project number 12921).

A prominent finding in this study is the need to involve patient-centered information in the MDT meeting and the MDT members' recommendation of corresponding strategies, such as methods for collecting it beforehand or by involving people in the MDT meeting who are aware of this information. This is in line with other studies. ${ }^{13,14,16}$ Our findings also confirm that decision-making in the MDT meeting is primarily based on medical information. ${ }^{15,16,42}$ Therefore, we propose improving the collection and use of patient-centered information in MDT 
meetings, which seems to be an essential first step towards patient-centered MDT decision-making.

A new finding in our study was that the MDT members voiced a need for more information following the MDT meeting to facilitate more patient-centeredness in the decisionmaking conversation with the patient. Subsequently, many of the recommended strategies aimed for thoroughly documenting and communicating the decision-making process. For example, by discussing and reporting treatment alternatives instead of providing one treatment recommendation. Or, when applicable, by arranging a joint consultation: such a "mini-MDT" may provide the patient with the opportunity to discuss the treatment alternatives with the relevant specialities, without attending the MDT meeting. Based on this finding, we propose strategies that facilitate the decisionmaking conversation with the patient following the MDT meeting, which could be regarded as the second essential step towards patient-centered MDT decision-making.

The recognition of these two steps seems crucial in transforming cancer-related decision-making to a patientcentered process. In practice, cancer-related decisionmaking is a process with interdependent decisional moments in which a MDT decision is embedded, instead of the MDT being a one-shot moment. ${ }^{15}$ Figure 1 depicts this decisionmaking process and the corresponding Shared DecisionMaking phases. ${ }^{43,44}$ The MDT is a crucial step in the decision-making process and currently patients usually do not participate in MDT meetings. Although currently patient participation in an MDT is being examined, ${ }^{45}$ our findings show that there was little support base for this strategy.
Therefore, implementing strategies involving both aforementioned essential steps may be a valuable alternative to involve the patient perspective in the decision-making process. Furthermore, although we did not regard patients as the primary source for this study, patients may think of additional strategies. ${ }^{16}$ These may be explored in the future.

Another notable finding is that some of the recommended strategies did not clearly relate to a voiced need. A first explanation may be that some strategies do not specifically address patient-centeredness, such as those regarding time pressure, chairing, or the education of young professionals. They frequently overlap with wellknown strategies that address the effectiveness of the meeting and the decision-making process. ${ }^{5,9,12,30}$ Taking in mind the definition of patient-centeredness, the MDT members may not have initially expressed corresponding needs. However, as they were elaborating during the interview, they may have thought of these strategies on second hand. Therefore, it is important to take in mind that other aspects of the MDT meeting, like organization and education, may be enablers of patient-centeredness. Second, some strategies not corresponding to a need originated from the list that was presented to the MDT members and did not arise spontaneously. This does not immediately implicate that these strategies should be discarded for implementation in practice. For example, displaying a patient photograph during the meeting is a quick and easily applicable strategy that was strongly supported. However, some of these strategies require more reflection. Our findings show that MDT members were ambiguous

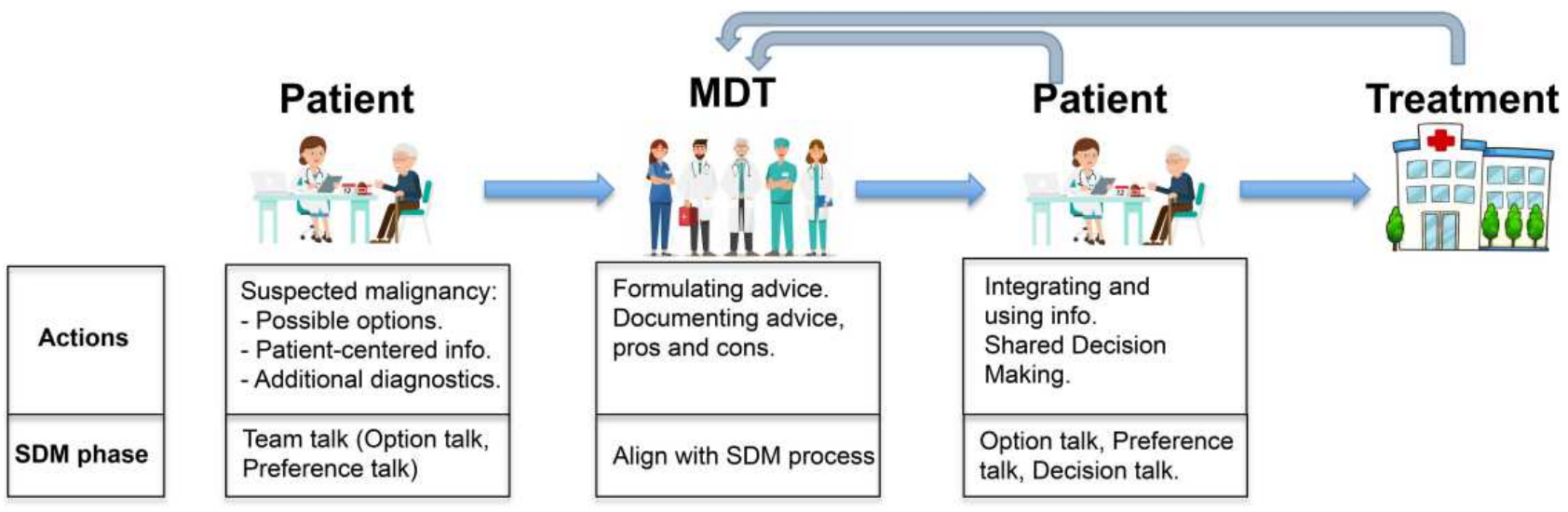

Figure I Cancer-related decision-making process. At suspicion of malignancy the physician discusses the possible diagnosis and treatment options with the patient (team talk and, if possible, option talk). Patient-centered information is acquired (preference talk) and additional diagnostics are ordered. The treating physician discusses the patient case in the MDT meeting, where an advice is formulated and well-documented. The team aims to align MDT decision-making with Shared Decision-Making with the patient. Then, the physician translates the MDT advice to the patient and integrates this with the patient towards a personalized treatment plan. Options are explained with pros and cons (option talk) and preferences are discussed (preference talk). The treatment is applied. During decision-making or treatment, the MDT may be consulted again, when necessary.

Abbreviation: SDM, Shared Decision-Making. 
about the training of chairs and other members on patientcenteredness or shared decision-making. However, leadership skills of the chair and team skills of the MDT are known to be important for effective decision-making. ${ }^{30,32}$ Therefore, improving patient-centeredness in MTDs by training, based on the local preferences, may still be a promising strategy.

One of the motives for this study was the recognition of several barriers to patient-centeredness. Connecting the strategies to underlying needs may increase the chance for successful implementation and subsequently, overcoming some of the aforementioned barriers. However, it should be noted that not all health care professionals will embrace these initiatives. Implementing supportive instead of activist-type strategies may help keeping all MDT members on board. For example, designating a co-chair with secretary role, to thoroughly report the MDT discussion with pros and cons for treatment options, may provoke discussing more than one option with the patient without being too much compelling.

\section{Strengths and Limitations}

Using explorative interviews with open-ended questions provided richer information on strategies than, for example, survey ${ }^{24}$ and a literature review ${ }^{5,30,32}$ methodologies. This lead to several novel strategies.

Some limitations may apply to our study. First, the use of multiple interviewers may have slightly impeded indepth questioning. Furthermore, by interviewing various MDT members from five different MDTs, we obtained rich information. This may explain why the sample was quite big to reach data saturation.

Second, the study was performed in our specific setting. As the composition and functioning of MDTs in different hospitals and countries may vary, this may affect the transferability of our findings. We recognized that there were differences between the five MDTs in our hospital, for example, to what extent the MDT discussed referral patients. MDTs without tertiary referral functions may less likely encounter patients only being referred "on paper" instead of physically attending the hospital. On the other hand, the majority of needs and strategies originated from professionals from various MDTs, suggesting transferability. We thoroughly described our MDT members and setting to aid others in making a judgment about the transferability to their situation.

An important footnote with regard to our findings is that we did not apply prioritizing exercises and therefore formally we cannot prioritize in the list of strategies. More research following these principles may gain insight into how to successfully implement these strategies.

\section{Conclusion}

Our findings highlight the MDT members' perceived need to improve patient-centeredness in MDTs. Various wellsupported strategies for improvement were recommend, that may be implemented in practice. Many strategies regard collecting and using patient-centered information before the MDT, such as patient-centered information, needs and preferences. Others regard facilitating the decision-making conversation with the patient following the MDT meeting. These strategies underscore the involvement of patients throughout the continuous process of decision-making for patients with cancer. Future research may aim to prioritize these and other strategies and to determine and evaluate the effect on endpoints, like patient or professional satisfaction, shared decision-making, and on the decision that was made.

\section{Abbreviations}

GP, general practitioner; MDT, multidisciplinary team; SDM, shared decision-making.

\section{Research Reporting Guidelines}

The study was reported according to the COREQ guidelines. The checklist is supplied as an additional file.

\section{Data Sharing Statement}

The NVivo dataset is not routinely available. Requests for the dataset can be submitted to the first author, accompanied by an explanatory letter.

\section{Consent for Publication}

All authors approved the final version of the manuscript.

\section{Acknowledgments}

The authors would like to thank the five participating MDTs for their openness, which allowed us to observe the meetings. We also acknowledge the participants who offered their time for the interviews and member checks and especially Chantal Hoge, for a critical review of the manuscript. We are grateful to the patients that participated in the focus groups, and finally, all other people that contributed to this study like those from the quality of care department. 


\section{Author Contributions}

Paulus A.F. Geerts is currently deployed at Department of Oncology, Isala Klinieken, Zwolle, The Netherlands. All authors made a significant contribution to the work reported, whether that is in the conception, study design, execution, acquisition of data, analysis and interpretation, or in all these areas; took part in drafting, revising or critically reviewing the article; gave final approval of the version to be published; have agreed on the journal to which the article has been submitted; and agree tob e accountable for all aspects of the work.

\section{Funding}

No funding declared.

\section{Disclosure}

No competing interests declared.

\section{References}

1. ASCO and ESMO. ASCO-ESMO consensus statement on quality cancer care. J Clin Oncol. 2006;24(21):3498-3499. doi:10.1200/ JCO.2006.07.4021

2. Borras JM, Albreht T, Audisio R, et al. Policy statement on multidisciplinary cancer care. Eur $J$ Cancer. 2014;50(3):475-480. doi:10.1016/j.ejca.2013.11.012

3. Pillay B, Wootten AC, Crowe H, et al. The impact of multidisciplinary team meetings on patient assessment, management and outcomes in oncology settings: a systematic review of the literature. Cancer Treat Rev. 2016;42:56-72. doi:10.1016/j.ctrv.2015.11.007

4. Basta YL, Bolle S, Fockens P, Tytgat K. The value of multidisciplinary team meetings for patients with gastrointestinal malignancies: a systematic review. Ann Surg Oncol. 2017;24(9):2669-2678. doi:10.1245/s10434-017-5833-3

5. Lamb BW, Brown KF, Nagpal K, Vincent C, Green JS, Sevdalis N. Quality of care management decisions by multidisciplinary cancer teams: a systematic review. Ann Surg Oncol. 2011;18(8):2116-2125. doi:10.1245/s10434-011-1675-6

6. Tremblay D, Roberge D, Touati N, Maunsell E, Berbiche D. Effects of interdisciplinary teamwork on patient-reported experience of cancer care. BMC Health Serv Res. 2017;17(1):218. doi:10.1186/s12913-017-2166-7

7. Castro EM, Van Regenmortel T, Vanhaecht K, Sermeus W, Van Hecke A. Patient empowerment, patient participation and patient-centeredness in hospital care: a concept analysis based on a literature review. Patient Educ Couns. 2016;99(12):1923-1939. doi:10.1016/j.pec.2016.07.026

8. Committee on Quality of Health Care in America, Institute of Medicine. Crossing the Quality Chasm: A New Health System for the 21st Century. Washington (DC): National Academies Press; 2001.

9. Kidger J, Murdoch J, Donovan JL, Blazeby JM. Clinical decision-making in a multidisciplinary gynaecological cancer team: a qualitative study. BJOG. 2009;116(4):511-517. doi:10.1111/j.14710528.2008.02066.x

10. Lanceley A, Savage J, Menon U, Jacobs I. Influences on multidisciplinary team decision-making. Int $J$ Gynecol Cancer. 2008;18 (2):215-222. doi:10.1111/j.1525-1438.2007.00991.x

11. Devitt B, Philip J, McLachlan S. Team dynamics, decision making, and attitudes toward multidisciplinary cancer meetings: health professionals' perspectives. J Oncol Pract. 2010;6(6):e17-e20. doi:10.1200/JOP.2010.000023
12. Jalil R, Ahmed M, Green JS, Sevdalis N. Factors that can make an impact on decision-making and decision implementation in cancer multidisciplinary teams: an interview study of the provider perspective. Int $J$ Surg. 2013;11(5):389-394. doi:10.1016/j. ijsu.2013.02.026

13. Hahlweg P, Hoffmann J, Harter M, Frosch DL, Elwyn G, Scholl I. In Absentia: an exploratory study of how patients are considered in multidisciplinary cancer team meetings. PLoS One. 2015;10(10): e0139921. doi:10.1371/journal.pone.0139921

14. Restivo L, Apostolidis T, Bouhnik AD, Garciaz S, Aurran T, JulianReynier C. Patients' non-medical characteristics contribute to collective medical decision-making at multidisciplinary oncological team meetings. PLoS One. 2016;11(5):e0154969. doi:10.1371/journal. pone. 0154969

15. Horlait M, Baes S, Dhaene S, Van Belle S, Leys M. How multidisciplinary are multidisciplinary meetings in cancer care? An observational study in oncology departments in Flanders, Belgium. $J$ Multidiscip Healthc. 2019;12:159-167. doi:10.2147/JMDH. S196660

16. Taylor C, Finnegan-John J, Green JSA. "No decision about me without me" in the context of cancer multidisciplinary team meetings: a qualitative interview study. BMC Health Serv Res. 2014;14 (488):1-11. doi:10.1186/1472-6963-14-1

17. Blazeby JM, Wilson L, Metcalfe C, Nicklin J, English R, Donovan JL. Analysis of clinical decision-making in multi-disciplinary cancer teams. Ann Oncol. 2006;17(3):457-460. doi:10.1093/annonc/mdj102

18. English R, Metcalfe C, Day J, Rayter Z, Blazeby JM; Breast cancer multi-disciplinary t. A prospective analysis of implementation of multi-disciplinary team decisions in breast cancer. Breast J. 2012;18 (5):459-463. doi:10.1111/j.1524-4741.2012.01270.x

19. Leo F, Venissac N, Poudenx M, Otto J, Mouroux J; Groupe d'Oncologie Thoracique A. Multidisciplinary management of lung cancer: how to test its efficacy? J Thorac Oncol. 2007;2(1):69-72. doi:10.1097/JTO.0b013e31802bff56

20. Raine R, Xanthopoulou P, Wallace I, et al. Determinants of treatment plan implementation in multidisciplinary team meetings for patients with chronic diseases: a mixed-methods study. BMJ Qual Saf. 2014;23(10):867-876. doi:10.1136/bmjqs-2014-002818

21. Rajan S, Foreman J, Wallis MG, Caldas C, Britton P. Multidisciplinary decisions in breast cancer: does the patient receive what the team has recommended? $\mathrm{Br} J$ Cancer. 2013;108 (12):2442-2447. doi:10.1038/bjc.2013.267

22. Strong S, Blencowe NS, Fox T, et al. The role of multi-disciplinary teams in decision-making for patients with recurrent malignant disease. Palliat Med. 2012;26(7):954-958. doi:10.1177/ 0269216312445296

23. Ung KA, Campbell BA, Duplan D, Ball D, David S. Impact of the lung oncology multidisciplinary team meetings on the management of patients with cancer. Asia Pac J Clin Oncol. 2016;12(2):e298-304. doi:10.1111/ajco.12192

24. Wood JJ, Metcalfe C, Paes A, et al. An evaluation of treatment decisions at a colorectal cancer multi-disciplinary team. Colorectal Dis. 2008;10(8):769-772. doi:10.1111/j.1463-1318.2007.01464.x

25. Lamb BW, Taylor C, Lamb JN, et al. Facilitators and barriers to teamworking and patient centeredness in multidisciplinary cancer teams: findings of a national study. Ann Surg Oncol. 2013;20 (5):1408-1416. doi:10.1245/s10434-012-2676-9

26. Baes S, Horlait M, Dhaene S, Leys M. Physicians' attitudes and perspectives regarding the uptake of psychosocial aspects and/or patient preferences during multidisciplinary team meetings in oncology. Int $J$ Care Coord. 2020;23:107-114. doi:10.1177/ 2053434520959678

27. Soukup T, Lamb BW, Morbi A, et al. A multicentre cross-sectional observational study of cancer multidisciplinary teams: analysis of team decision making. Cancer Med. 2020:1-17. 
28. Soukup T, Lamb BW, Shah NJ, et al. Relationships between communication, time pressure, workload, task complexity, logistical issues and group composition in transdisciplinary teams: a prospective observational study across 822 cancer cases. Front Commun. 2020;5:1-12.

29. Geerligs L, Rankin NM, Shepherd HL, Butow P. Hospital-based interventions: a systematic review of staff-reported barriers and facilitators to implementation processes. Implement Sci. 2018;13(1). doi: 10.1186/s13012-018-0726-9

30. Fleissig A, Jenkins V, Catt S, Fallowfield L. Multidisciplinary teams in cancer care: are they effective in the UK? Lancet Oncol. 2006;7 (11):935-943. doi:10.1016/S1470-2045(06)70940-8

31. Soukup T, Lamb BW, Sarkar S, et al. Predictors of Treatment Decisions in Multidisciplinary Oncology Meetings: a Quantitative Observational Study. Ann Surg Oncol. 2016;23(13):4410-4417. doi:10.1245/s10434-016-5347-4

32. Soukup T, Lamb BW, Arora S, Darzi A, Sevdalis N, Green JS. Successful strategies in implementing a multidisciplinary team working in the care of patients with cancer: an overview and synthesis of the available literature. $J$ Multidiscip Healthc. 2018;11:49-61. doi:10.2147/JMDH.S117945

33. Epstein RM, Duberstein PR, RFenton JJ, et al. Effect of a patient-centered communication intervention on oncologist-patient communication, quality of life, and health care utilization in advanced cancer: the VOICE randomized clinical trial. JAMA Oncol. 2017;3(1):92-100. doi:10.1001/jamaoncol.2016.4373

34. Fried TR, Tinetti M, Agostini J, Iannone L, Towle V. Health outcome prioritization to elicit preferences of older persons with multiple health conditions. Patient Educ Couns. 2011;83(2):278-282. doi:10.1016/j.pec.2010.04.032

35. Savelberg W, van der Weijden T, Boersma L, Smidt M, Willekens C, Moser A. Developing a patient decision aid for the treatment of women with early stage breast cancer: the struggle between simplicity and complexity. BMC Med Inform Decis Mak. 2017;17(1):112. doi:10.1186/s12911-017-0505-6
36. Schuling J, Sytsema R, Berendsen AJ. Aanpassen medicatie: voorkeur oudere patient telt mee[Changing medication: the preferences of elderly patients also count]. Ned Tijdschr Geneeskd. 2013;157 (A6491):1-5.

37. Kallio H, Pietila AM, Johnson M, Kangasniemi M. Systematic methodological review: developing a framework for a qualitative semi-structured interview guide. $J$ Adv Nurs. 2016;72 (12):2954-2965. doi:10.1111/jan.13031

38. Epstein RM, Gramling RE. What is shared in shared decision making? Complex decisions when the evidence is unclear. Med Care Res Rev. 2013;70(1 Suppl):94S-112S. doi:10.1177/1077558712459216

39. Hsieh HF, Shannon SE. Three approaches to qualitative content analysis. Qual Health Res. 2005;15(9):1277-1288. doi:10.1177/ 1049732305276687

40. Elo S, Kyngas $\mathrm{H}$. The qualitative content analysis process. $J A d v$ Nurs. 2008;62(1):107-115. doi:10.1111/j.1365-2648.2007.04569.x

41. Kerr C, Nixon A, Wild D. Assessing and demonstrating data saturation in qualitative inquiry supporting patient-reported outcomes research. Expert Rev Pharmacoecon Outcomes Res. 2010;10 (3):269-281. doi:10.1586/erp.10.30

42. Hamilton DW, Heaven B, Thomson RG, Wilson JA, Exley C. Multidisciplinary team decision-making in cancer and the absent patient: a qualitative study. BMJ Open. 2016;6(7):e012559. doi:10.1136/bmjopen-2016-012559

43. Stiggelbout AM, Pieterse AH, De Haes JCJM. Shared decision making: concepts, evidence, and practice. Patient Educ Couns. 2015;98 (10):1172-1179. doi:10.1016/j.pec.2015.06.022

44. Elwyn G, Durand AM, Song J, et al. A three-talk model for shared decision making: multistage consultation process. BMJ. 2017;359: j4891. doi:10.1136/bmj.j4891

45. Heuser C, Diekmann A, Ernstmann N, Ansmann L. Patient participation in multidisciplinary tumour conferences in breast cancer care (PINTU): a mixed-methods study protocol. BMJ Open. 2019;9(4): e024621. doi:10.1136/bmjopen-2018-024621
Journal of Multidisciplinary Healthcare

\section{Publish your work in this journal}

The Journal of Multidisciplinary Healthcare is an international, peerreviewed open-access journal that aims to represent and publish research in healthcare areas delivered by practitioners of different disciplines. This includes studies and reviews conducted by multidisciplinary teams as well as research which evaluates the results or conduct of such teams or healthcare processes in general. The journal covers a very wide range of areas and welcomes submissions from practitioners at all levels, from all over the world. The manuscript management system is completely online and includes a very quick and fair peer-review system. Visit http://www.dovepress.com/testimonials. php to read real quotes from published authors. 